\title{
Correspondence
}

\section{Awareness during anaesthesia - patient view}

To the Editor:

I have recently been operated upon for an ovarian cyst. Although I survived, the experience was traumatic. During the operation I was awake and experienced severe pain and the trauma of being unable to move, scream or communicate.

After relating my experience to the anaesthetist I was told that I was one of $2 \%$ of patients who have recall although this figure is contradicted by a UK study that recognizes one in a thousand. Whatever the percentage, it seems to be accepted by the Medical Profession but it is not acceptable to anyone who has endured this complication.

I understand that when I awoke and was aware and in pain, it was most likely when the ultra short acting agent was wearing off and the lightest of anaesthetics had not yet kicked in. Why is this chance at the expense of the patient allowed? Was it for technical prowess and rapid awakening that I was not given enough anaesthesia? Is it possible to return to the practice of slightly deeper anaesthesia without compromising safety? The patients' welfare should take precedence over a "rapid turn around" and other measures to minimize hospital stay. I was also told that there is no way of determining if the patient is awake. Surely, knowing this and accepting that some patients will be paralyzed and aware, pre-medication, longer acting drugs and a deeper anaesthetic should be given?

I am writing to ask you, the anaesthetists, please reassess the philosophy and practice of modern anaesthesia so that no more patients suffer.

Joan Hoogewerf.

Mission, B.C.

\section{Desflurane and nausea following ondansetron premedication}

To the Editor:

We wish to report our experience in 120 patients at the University of Wisconsin following laparoscopic tubal banding at risk for postoperative nausea, with either desflurane or propofol anaesthesia with ondansetron premedication, $4 \mathrm{mg} i \mathrm{v}$.

All patients were premedicated with $0.03 \mathrm{mg} \cdot \mathrm{kg}^{-1}$ midazolam and $15 \mu \mathrm{g} \cdot \mathrm{kg}^{-1}$ alfentanil $i v .60 \mathrm{had}$ desflurane anaesthesia following anaesthesia induction with $10 \mathrm{mg} \cdot \mathrm{kg}^{-1}$ methohexitone iv and the remaining propofol. Atracurium was used and reversed if indicated. Postoperatively the incidence of nausea and vomiting was assessed at 60,90 and $120 \mathrm{~min}$ and compared using a student's $t$ test, $P<0.05$. Nausea was more frequent in the desflurane group (Table).

It appears that, following iv ondansetron premedication, in patients at risk for nausea, desflurane may be an inferior choice as compared to propofol.

George A. Arndt MD

Madison, Wisconsin, USA

TABLE

\begin{tabular}{lllllll}
\hline & \multicolumn{3}{c}{ Propofol } & \multicolumn{3}{c}{ Desflurane } \\
\hline Time & 60 & 90 & 120 & 60 & 90 & 120 \\
Nausea & & & & & & \\
incidence & $12 \%$ & $13 \%$ & $17 \%$ & $32 \%$ & $37 \%$ & $37 \%$ \\
& $P<.05$ & $P<.05$ & $P<.05$ & & & \\
\hline
\end{tabular}

\section{Sevoflurane for oesophagoscopy in a patient with myotonic dystrophy}

To the Editor:

We report the management of a 62 -yr-old man with myotonic dystrophy scheduled for flexible oesophagoscopy. Dystrophia myotonica is the most common of the myotonias and presents the anaesthetist with a variety of problems related to the use of muscle relaxants and unpredictable sensitivity to opioids, barbiturates and benzodiazepines. ${ }^{1-3}$ The use of propofol in such patients has been reported as exacerbating the muscular weakness. ${ }^{4}$

Sevoflurane was used as the prime anaesthetic agent. Sevoflurane is non-irritant to the airways with a low blood- gas solubility coefficient, characteristics which lend themselves well to employing a single-breath 